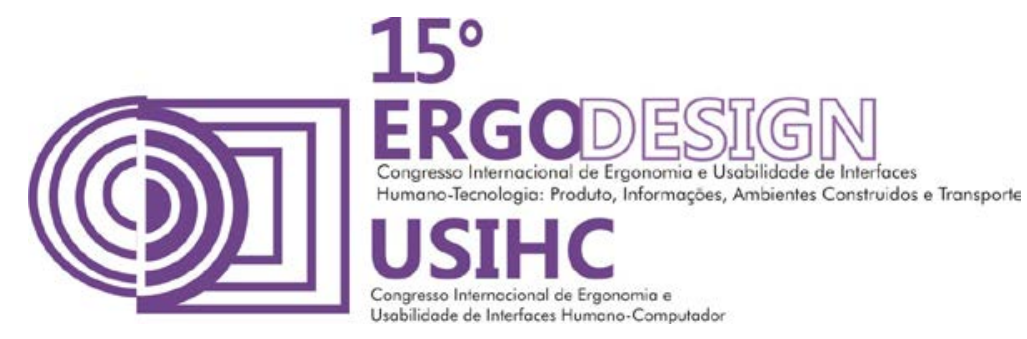

\title{
ERGONOMIA EM RÓTULOS DE MEDICAMENTOS: UMA ANÁLISE A PARTIR DE PRINCÍPIOS DO CONFORTO VISUAL
}

\section{ERGONOMICS IN MEDICINE PACKAGING: AN ANALYSIS FROM PRINCIPLES OF VISUAL COMFORT}

\author{
BLUM, Arina (1); \\ MERINO, Eugenio Andrés Díaz (2) \\ (1) Universidade Federal de Santa Catarina, Mestre \\ e-mail: arinablum@gmail.com \\ (2) Universidade Federal de Santa Catarina, Doutor \\ e-mail: eugenio.merino@ufsc.br
}

\begin{abstract}
RESUMO
No Brasil, os rótulos de medicamentos são regulamentados pela Anvisa, que estabelece as diretrizes para as embalagens de fármacos. Este artigo apresenta o estudo que objetivou analisar as questões ergonômicas visuais relativas ao rótulo de medicamentos, especialmente as diretrizes que apontem para aspectos da legibilidade. Partiu da problemática que buscou entender se definições que concernem a ergonomia visual estão contempladas na regulamentação específica. A pesquisa utilizou-se de uma investigação qualitativa exploratória de natureza aplicada. Como resultados, são apontadas características que podem assinalar futuras proposições de melhorias em embalagens de medicamentos.
\end{abstract}

Palavras-chave: design, ergonomia, legibilidade, embalagem

\section{ABSTRACT (11 PTS, NEGRITO)}

The drug labels in Brazil are regulated by the Brazilian Health Surveillance Agency (Anvisa), which establishes the guidelines for drug packaging. This article presents the study that aimed to analyze the visual ergonomic standards related to the drugs labels, especially the guidelines that point to aspects of readability. It started from the problematic that sought to understand whether the issues concerning visual ergonomics are within the specific regulation, using a qualitative exploratory research of applied nature. As results, some features that may contribute to future proposals of improvements on the drugs packages. Keywords: design, ergonomics, legibility, packaging 


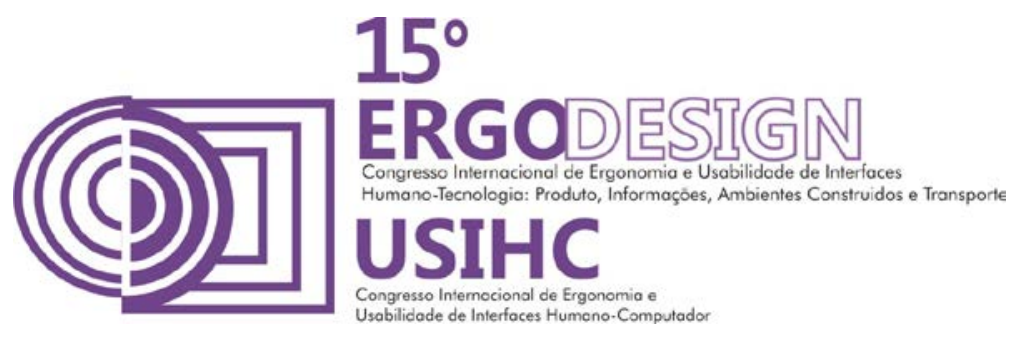

\section{INTRODUÇÃO}

A construção de mensagens visuais tem relação direta com os conhecimentos, as atitudes e o comportamento das pessoas, sendo que, através do design, tem-se o desenvolvimento de estratégias que usam os elementos visuais para implementar e identificar algo (Frascara, 2000). Neste contexto se aplica o desenvolvimento de embalagens, sendo que estas se constituem de funções específicas de ordem tecnológica, mercadológica, de aspectos logísticos, econômicos e funcionais, de finalidade, de proteção, de aparência e conceito (Gurgel, 2007). Mais objetivamente, a embalagem tem a função de proteger e identificar o produto.

No campo da ergonomia visual dirigida aos medicamentos, pesquisas demostram que o design informacional aplicado de maneira equivocada leva à falta de conforto ocasionado pela não legibilidade plena. Entre tais estudos, citam-se os realizados por Cavaco e Santos (2012); Kamisaki, Nascimentos e Santos (2011); Spinillo, Padovani e Lanzoni (2010); Paula el al (2009); Cossío (2008); Fujita e Spinillo (2008); Waarde (2008); Lima (2007) e Fujita (2004). Estes se concentram, especialmente, na análise de bulas e concordam que a legibilidade prejudicada na assimilação do conteúdo informacional do medicamento - seja para entender o seu uso, seja para captar a informação que o identifica - advém da disposição equivocada de elementos gráficos; fato também aplicável às suas embalagens.

No caso específico de medicamentos no âmbito brasileiro, a normativa da Agência Nacional de Vigilância Sanitária (Anvisa) estabelece diretrizes, a RDC 71/2009, que visam "aprimorar a forma e o conteúdo dos rótulos de todos os medicamentos registrados e comercializados no Brasil, visando garantir o acesso à informação segura e adequada em prol do uso racional de medicamentos" (BRASIL, 2009). Trata-se de um regulamento técnico que regra a rotulagem de medicamentos registrados no Ministério da Saúde. Junto à RDC 71/2009, a Anvisa comunica modelos de embalagens que auxiliam fabricantes quanto às diretrizes visuais normatizadas, ao mesmo tempo que explicam (visualmente) os elementos dispostos na regulamentação.

O objetivo da pesquisa relatada neste artigo foi de analisar as questões ergonômicas visuais relativas ao rótulo de medicamentos usando, para tanto, princípios de ergonomia visual especificamente diretrizes que apontem para aspectos da legibilidade em embalagens buscados em literatura especializada. Partindo da dúvida se as definições que concernem a ergonomia visual estão contempladas nas regras que especificam a rotulagem de medicamentos, a análise estruturou-se através de uma investigação qualitativa exploratória de natureza aplicada, apoiada nas pesquisas bibliográfica e documental.

Como procedimentos metodológicos, a partir de uma revisão bibliográfica, princípios da ergonomia visual, no âmbito da legibilidade, leiturabilidade e visibilidade, foram coletados e utilizados como indicativos para o estudo de uma embalagem de medicamento. Ainda, levantando documentos que regram a rotulagem de medicamentos, a pesquisa concentrou-se em um modelo específico de embalagem secundária apresentada pela Ministério da Saúde, entendendo que este é um exemplar que, entre outros, representa visualmente a transposição das regras dispostas nas diretrizes da Anvisa e que pode, desta forma, ser base para a análise impulsionadora desta investigação e de outras futuras. 


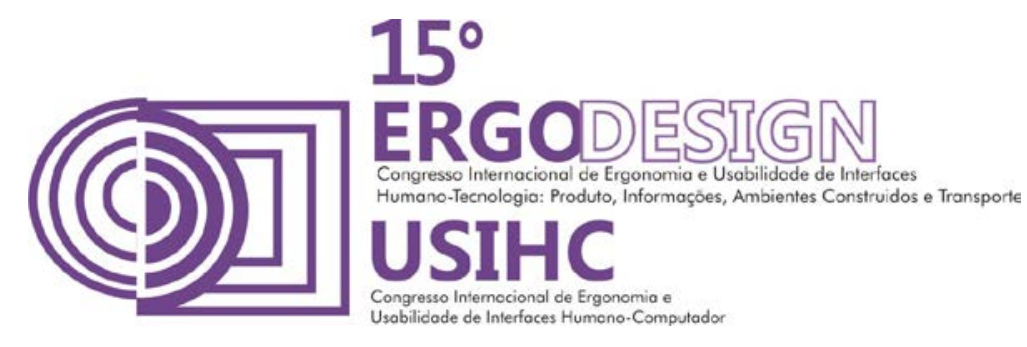

\section{CONSIDERAÇÕES SOBRE ERGONOMIA VISUAL}

Por ergonomia visual compreende-se, neste estudo, as questões relativas à qualidade de leitura (legibilidade, leiturabilidade e visibilidade) em termos de menos esforço e incorrência a erros. Trata do conforto visual e o uso do design para tanto. O conforto visual é especialmente necessário em embalagens de fármacos, visto que a identificação correta (e muitas vezes rápida) do medicamento - na dispensação em farmácia e na manipulação pelo usuário - é fator primordial para se evitar o erro que pode levar a graves danos à saúde. A identificação da embalagem pode ocorrer também em momento de estresse pela urgência - em caso de uso emergencial do medicamento em uma situação extremada, por exemplo (SPINILLO; PADOVANI; LANZONI, 2010) - e a embalagem precisa transmitir as informações de maneira clara e rápida.

A embalagem, incluída entre os tradicionais sistemas gráficos informacionais, pode apresentar problemas quanto aos aspectos ergonômicos, resultando no impedimento de efetiva percepção da informação (PASCHOARELLI; BONFIM, 2013). Hellebek (2013), com relação às embalagens de medicamento, coloca que a segurança do paciente também se relaciona a ela, já que erros de medicação podem ser fruto de problemas de interação com o usuário. Para a autora, apurar o projeto do rótulo pode melhorar a segurança do paciente já no processo de medicação, concluindo, desta forma, que é relevante analisar a relação dos erros de interpretação de rótulos com o design desses rótulos.

Tal relação pode ser estabelecida com a corroboração de Tonetto, Renck e Stein (2012) que, ao falarem sobre o processo de cognição nas tomadas de decisão e a relação com o design, citam que as pessoas são sensíveis não apenas ao conteúdo da informação em si, mas também à forma com essas informações são passadas. A embalagem, como um meio para comunicar o conteúdo informacional que envolve o medicamento, estrutura-se no design e nos elementos ergonômicos visuais - tal como a legibilidade - para efetivar-se enquanto sistema de informação (PASCHOARELLI; BONFIM, 2013). Martins (2008, p. 60), contudo, ao relatar uma pesquisa sobre legibilidade em receitas médicas, afirma que a legislação na área da saúde é imprecisa quanto ao termo "legível", especialmente porque ignora fatores dos quais dependem a compreensão do usuário, tais como: o contexto de leitura, a estética, as experiências prévias de quem lê, a qualidade linguística e a leiturabilidade.

A legibilidade, a leiturabilidade e a visibilidade são algumas das maneiras de informar o conteúdo de uma embalagem, sendo que, no caso de medicamentos, grande parte dessas informações encontram-se em forma de texto. Fontoura e Fukushima (2012) explicam que a legibilidade refere-se ao desenho das letras, a leiturabilidade à compreensão do texto e da linguagem e a visibilidade à identificação do texto tomada uma certa distância. Tais conceitos são pertinentes a um estudo de ergonomia visual e são utilizados neste artigo através de desdobramentos que os delineiam.

O processo de percepção de letras envolve reconhecimento de padrões visuais que se ligam com informações já conhecidas por nós e que se encontram em nossa memória. É o que relata Farias (2013), ao explicar uma série de pesquisas que estudaram a identificação de textos pelas pessoas. Tal identificação, especialmente a percepção de palavras e letras, estão relacionadas ao que se encontra em nossa memória. Numa colocação breve e sem pretensão de aprofundamento, poderíamos supor que um dos problemas na identificação que a 


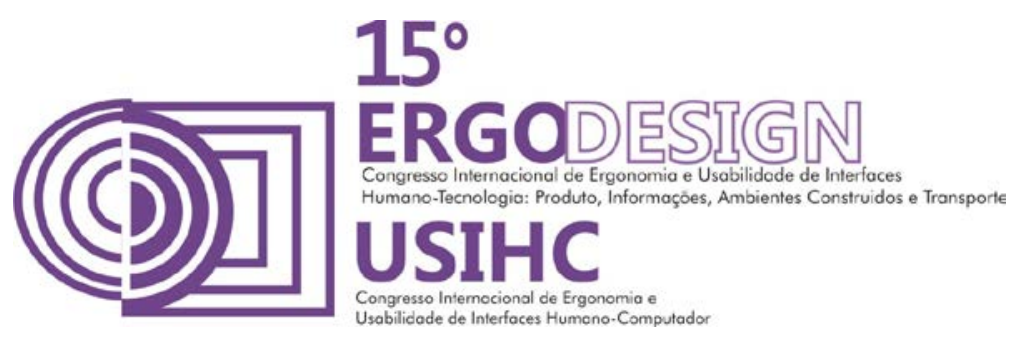

embalagem de medicamentos proporciona é o uso de uma linguagem desconhecida para grande parte dos usuários.

Legibilidade e leiturabilidade prejudicadas pelo excesso de informações e pelo uso de linguagem técnico-científica seriam responsáveis, segundo Kamisaki, Nascimento e Santos (2011), por dificultar a eficácia da comunicação entre fabricante e usuário, no caso de um estudo sobre bulas e cartelas de medicamentos. Textos, hierarquia e construção gráfica foram alguns dos elementos estudados pelos autores. Neste sentido, cabe verificar que elementos visuais potencialmente indicam erros de comunicação e que podem, por outro lado, serem analisados a fim de se detectar necessidades de melhoria.

A ergonomia visual, desta forma, encontra-se em consonância com os próprios conceitos de usabilidade, que é a medida "na qual um produto pode ser usado por usuários específicos para alcançar objetivos específicos com eficácia, eficiência e satisfação em um contexto específico de uso" (ABNT, 2002, p. 3). Neste sentido, entende-se que abordagem da ergonomia visual considerando os aspectos da legibilidade - e os elementos gráficos para tanto, tais como forma do texto, cores utilizadas, ilustrações e composição gráfica - é um dos passos para compreender o próprio produto - no caso a embalagem de medicamentos - bem como os problemas que se observam a partir da maneira como são dispostas as informações na rotulagem.

\section{ROTULAGEM DE MEDICAMENTOS}

A cadeia produtiva da embalagem é ampla e engloba uma série de atores, tais como os relacionados a engenharia, ao marketing, ao design e os setores ligados ao financeiro, ao legal e à produção industrial (Moura; Banzato, 1997). Profissionais de diversas áreas estão envolvidos no processo a fim de dar conta das funções da embalagem. Entre as funções, o aspecto comunicacional da rotulagem apresenta-se como essencial nas embalagens de medicamentos, sendo que a devida identificação (e a correta apresentação da informação ao público) é essencial para conferir, entre outros fatores, a segurança ao usuário.

A informação, segundo Gimeno (2000), está entre as principais funções comunicacionais da embalagem, sendo que ela é que estabelece a conexão entre o usuário e o produto. Em embalagens de medicamentos, a comunicação em todos os seus aspectos é relevante, na medida em que, segundo a Anvisa, em Brasil (2010), "a embalagem, o rótulo e a bula dos medicamentos devem transmitir todas as informações relevantes sobre o produto, contribuindo para o seu uso adequado". Tais informações são visualmente configuradas e aplicadas na embalagem a partir de resoluções publicadas pela Anvisa e a indústria responsável pelo medicamento tem obrigação legal de segui-las.

Neste sentido, a RDC 71 da Anvisa (BRASIL, 2009) estabelece diretrizes para os rótulos de medicamentos, tanto instituindo as informações que devem constar na embalagem quanto citando algumas disposições gráficas a serem nele aplicadas. A partir da RDC 71/09, surgiram resoluções estabelecidas para complementar ou aprofundar questões relativas ao design visual da embalagem, entre elas cita-se a RDC 21 (BRASIL, 2012) que institui o Manual de Identidade Visual de Medicamentos do Ministério da Saúde e nele indica questões tais como formas, tipografia, cores, proporções e disposições de textos e demais elementos visuais obrigatórios nas embalagens. 


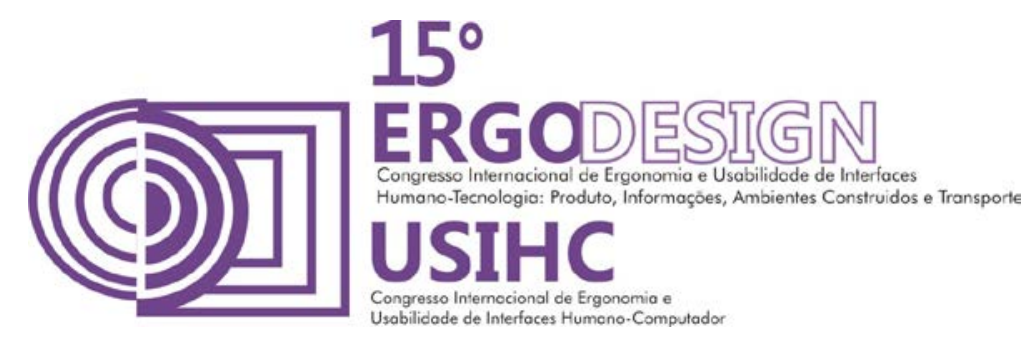

Quanto às nomenclaturas relativas aos tipos de embalagens, a RDC 71/2009 explica diferenciando os tipos. Este estudo se concentra na embalagem do tipo secundária, aquela que é externa ao produto, e no rótulo, que é a identificação impressa ou litografada diretamente sobre recipientes, vasilhames, invólucros, envoltórios ou qualquer outro protetor de embalagem. A Anvisa (BRASIL, 2014), ao comentar sobre a importância da rotulagem em um medicamento, explica que as informações no rótulo e na bula contribuem positivamente para o tratamento do paciente, já que neles são informados os benefícios e os riscos envolvidos, além dos cuidados a serem tomados. Explica que

a rotulagem dos medicamentos contém informações que possibilitam a identificação do medicamento durante sua dispensação e uso, o armazenamento adequado dos produtos, $o$ rastreamento do medicamento da sua fabricação até o consumo, bem como orientações quanto ao uso seguro do medicamento.

Cabe, para este estudo, ressaltar que a RDC 71/09 expande as questões gráficas para além dos quesitos visuais, apontando, por exemplo, a obrigatoriedade de que as embalagens secundárias contenham a identificação também pelo sistema Braille e que este deve ser aplicado "sem afetar a legibilidade das informações" (Art. 24). A questão da legibilidade aparece citada diversas vezes na RDC 71/09, como no Art. 19 que fala de textos que "devem ser impressos nas embalagens de medicamentos de forma facilmente compreensível, legível e indelével, utilizando letras com a maior dimensão possível para a sua fácil leitura e identificação em expressões" ou no $\S 1^{\circ}$ (Art. 19) que diz que legibilidade "destas informações deve ser garantida sem a utilização de instrumentos ópticos, a não ser para aquelas pessoas que necessitem de correção visual". É relevante, neste sentido, a realização de estudos que venham a verificar a ergonomia visual nas embalagens de medicamentos, assim auxiliando na inferência de melhorias que contribuam para a devida legibilidade provinda dos rótulos.

\section{ANÁLISE DE UMA EMBALAGEM SECUNDÁRIA}

A pesquisa consistiu-se de uma análise comparativa a partir de recomendações dispostas em literatura - quanto a ergonomia visual em materiais gráficos - em relação à um modelo de embalagem secundária proposta no Manual de Embalagens de Medicamentos (ANVISA, 2012) - documento que explana o padrão visual das embalagens de medicamentos a serem distribuídos pelo Ministério da Saúde à população brasileira pelo SUS. O estudo concentrou-se na análise da parte frontal de tal embalagem, considerando ser esta uma pesquisa inicial de uma investigação mais ampla e, ainda, tendo como hipótese que a parte frontal da embalagem é aquela que primeiro a identifica para o usuário. A fim de obter maior aprofundamento nos itens gráficos a serem analisados, a face foi particionada em áreas (Figura 1) aleatoriamente nomeadas de A, B, C, D, E, F e G. 

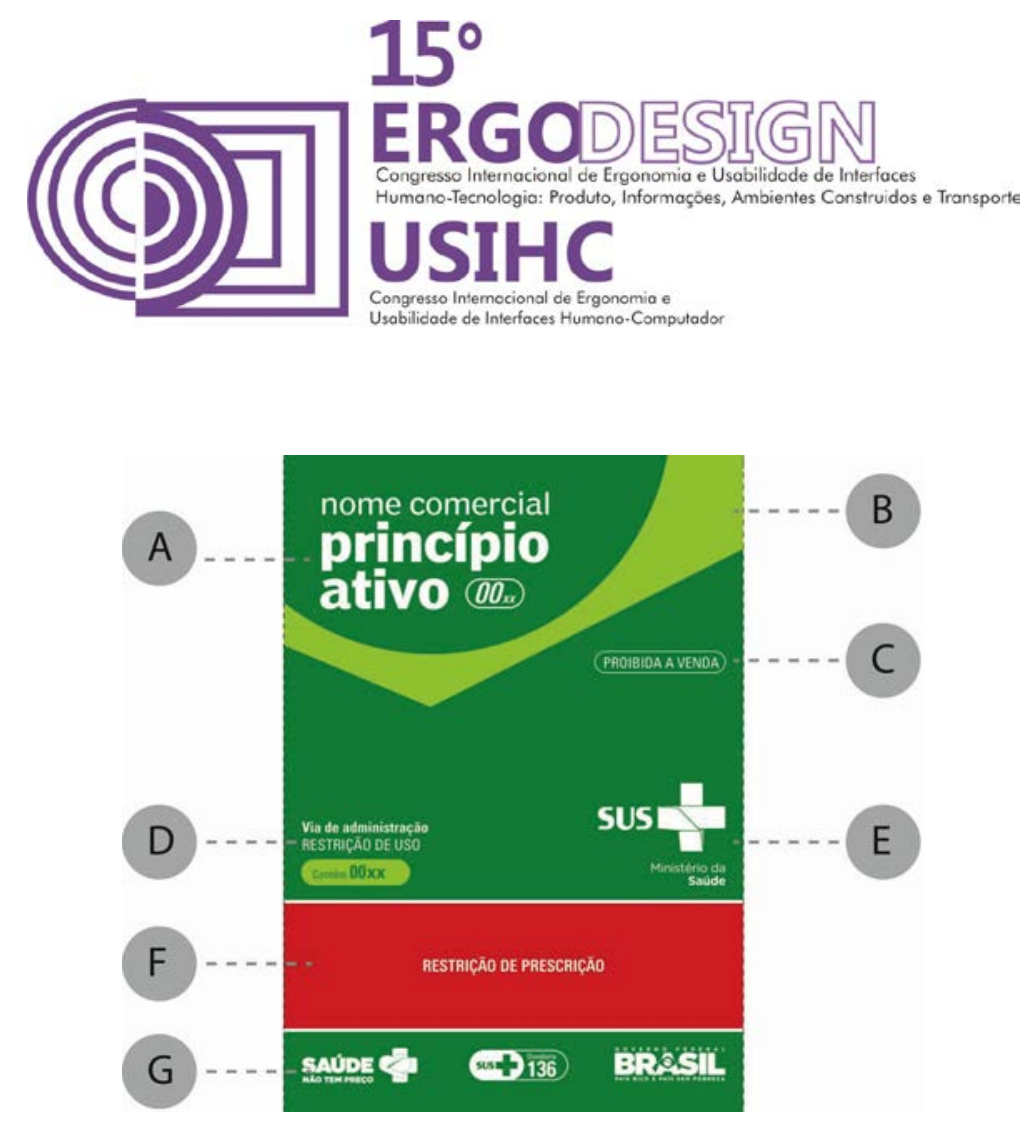

Figura 1 - Divisão da face frontal da embalagem em áreas para análise. Fonte: montagem para a pesquisa com base em Anvisa (2012, p. 21).

A área A refere-se ao título do produto, constando "nome comercial", "princípio ativo" e sua composição. A área $B$ refere-se a mancha gráfica que faz menção à bandeira brasileira através de um desenho geometrizado. A área $C$ indica o dizer "proibida a venda". A área D une os textos "via de administração" e "restrição de uso" ao indicativo do conteúdo da embalagem. A área E refere-se a assinatura visual do SUS - Ministério da Saúda. A área F é a tarja vermelha com a inscrição "restrição de prescrição". A área $G$ se refere a parte inferior da face frontal, onde constam logotipos relativos aos programas na área da saúde.

Para analisar a embalagem, indicações quanto à legibilidade de impressos foram coletadas em literatura especializada. Indicativos dos seguintes materiais foram utilizados: Farias (2013); Fontoura; Fukushima (2012); Gomes Filho (2012); Kamisaki; Nascimento; Santos (2011); European Commission (2009); Lima (2007); Dondis (2007); lida (2005); Plain English Campaing (2001 e 2007); Committee on Safety of Medicines (2005). Destes materiais, foram selecionadas recomendações referentes especialmente à legibilidade a partir do uso de textos e a relação deles com o todo do leiaute, considerando aspetos de relativos à composição por meio de cores e símbolos gráficos e os elementos da Gestalt.

A partir das referências, trinta indicações foram estabelecidas: (1) Letras simples - sem serifa ou pouca serifa; (2) Caixa-alta somente no início da frase; (3) Altura da letra acima de $4 \mathrm{~mm}$ para distância à $60 \mathrm{~cm}$; (4) Entrelinha pelo menos 1/30 do comprimento; (5) Alinhamento do texto à esquerda; (6) Não uso do hífen; (7) Não uso de versalete; (8) Tipos com contraste na forma das letras; (9) Tipos com ascendentes e descendentes destacadas; (10) Não uso de condensed; (11) Não uso de extended; (12) Comprimento da linha; (13) Não uso de itálico; (14) Variação no desenho de tipos; (15) Uso de símbolos e/ou pictogramas claros; (16) Cor não é a única forma de compreender a informação; (17) Leitura da esquerda para direita; (18) Hierarquia das informações; (19) Margens adequadas; (20) Espaço formando blocos de informação; (21) Não uso de marcas d'água; (22) Contraste figura-fundo; (23) (Gestalt) 


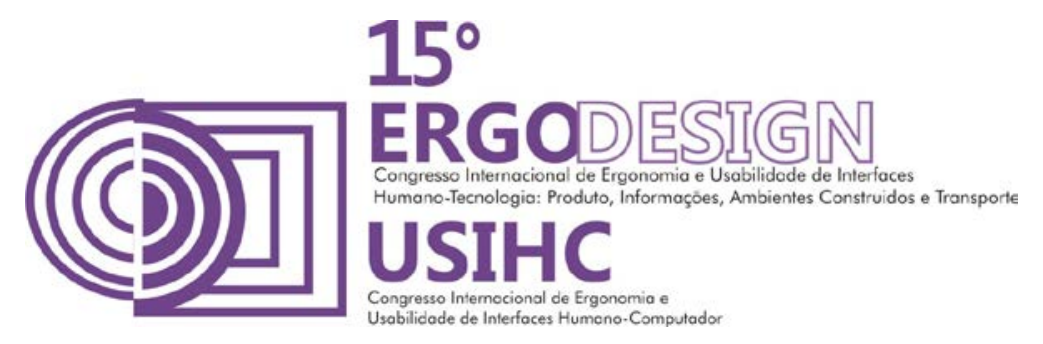

Unidade; (24) (Gestalt) Segregação; (25) (Gestalt) Unificação; (26) (Gestalt) Fechamento; (27) (Gestalt) Continuidade; (28) (Gestalt) Proximidade; (29) (Gestalt) Semelhança; (30) (Gestalt) Simetria. Tais indicações foram aleatoriamente numeradas apenas por uma questão de identificação dos itens a serem analisados, sendo que os números não se configuram como elementos de hierarquização.

Comparando a embalagem secundária (indicada na Figura 1) com cada uma das trinta indicações, gerou-se uma planilha (Quadro 1) que apresenta a análise e o parecer do estudo. Com relação ao parecer, este concentrou-se em verificar se a embalagem em questão estava de acordo com as indicações ou se novos estudos poderão ser realizados a fim de melhorar o aspecto analisado.

\section{Quadro 1 - Parecer da análise da embalagem a partir das indicações dispostas em literatura.}

\begin{tabular}{|c|c|c|}
\hline INDICAÇÕES & ANÁLISE & PARECER \\
\hline $\begin{array}{l}\text { (1) Letras simples - } \\
\text { sem serifa ou pouca } \\
\text { serifa }\end{array}$ & $\begin{array}{l}\text { Todas as fontes presentes na face analisada } \\
\text { apresentam-se sem serifa, como nas áreas } C \text { e F, ou } \\
\text { com pouca serifa, como na área } A \text {. }\end{array}$ & De acordo com as indicações. \\
\hline $\begin{array}{l}\text { (2) Caixa-alta } \\
\text { somente no início da } \\
\text { frase }\end{array}$ & $\begin{array}{l}\text { Área A somente em caixa-baixa, facilitando a } \\
\text { legibilidade neste sentido. Informações em C e F } \\
\text { totalmente em caixa-alta, assim como "restrição de } \\
\text { uso" na área D e logotipo nas assinaturas visuais (em } \\
\text { E e G). As informações em caixa-alta parecem } \\
\text { estarem configuradas desta maneira com o fim de } \\
\text { destaque da informação. }\end{array}$ & $\begin{array}{l}\text { Realizar estudos em que as } \\
\text { informações em caixa-alta } \\
\text { observadas em C, D e F se } \\
\text { destaquem utilizando caixa- } \\
\text { baixa. }\end{array}$ \\
\hline $\begin{array}{l}\text { (3) Altura da letra } \\
\text { acima de } 4 \mathrm{~mm} \text { para } \\
\text { distância à } 60 \mathrm{~cm}\end{array}$ & $\begin{array}{l}\text { O manual não informa precisamente a altura da letra e } \\
\text { sim determina a altura do tipo de "princípio ativo" como } \\
\text { "x". Desta forma, considerando o exemplo de } \\
\text { embalagem proposta e o título "princípio ativo" com } \\
4 \mathrm{~mm} \text {, a face precisaria ter } 9 \mathrm{~cm} \text { de altura, sendo que a } \\
\text { área G corresponderia a } 1 \mathrm{~cm} \text { deste total. }\end{array}$ & $\begin{array}{l}\text { Realizar estudos analisando o } \\
\text { tamanho das letras em } \\
\text { diferentes formatos de } \\
\text { embalagens. }\end{array}$ \\
\hline $\begin{array}{l}\text { (4) Entrelinha pelo } \\
\text { menos } 1 / 30 \text { do } \\
\text { comprimento }\end{array}$ & $\begin{array}{l}\text { No exemplo apresentado no manual, a entrelinha de } \\
\text { "princípio ativo" precisaria ser dobrada para chegar } \\
\text { nas recomendações. Entrelinha na área D está de } \\
\text { acordo. }\end{array}$ & $\begin{array}{l}\text { Realizar estudos de } \\
\text { entrelinha, especialmente no } \\
\text { título, verificando a } \\
\text { visualização a partir do } \\
\text { comprimento da denominação } \\
\text { do "princípio ativo". }\end{array}$ \\
\hline $\begin{array}{l}\text { (5) Alinhamento do } \\
\text { texto à esquerda }\end{array}$ & $\begin{array}{l}\text { Os textos estão alinhados à esquerda, considerando } \\
\text { aqueles que se apresentam em mais de uma linha } \\
\text { (áreas A e D) e desconsiderando aqueles que se } \\
\text { tratam de configurações de assinaturas visuais ou } \\
\text { similares (áreas E e G). }\end{array}$ & De acordo com as indicações. \\
\hline (6) Não uso do hífen & Nenhum dos textos se apresenta com hífen. & De acordo com as indicações. \\
\hline $\begin{array}{l}\text { (7) Não uso de } \\
\text { versalete }\end{array}$ & $\begin{array}{l}\text { Nenhum dos textos se apresenta na forma de } \\
\text { versalete. }\end{array}$ & De acordo com as indicações. \\
\hline
\end{tabular}




\section{(C)] USIHC}

\section{(8) Tipos com contraste na forma das letras \\ (9) Tipos com \\ ascendentes e \\ descendentes \\ destacadas}

\section{(10) Não uso de condensed}

(11) Não uso de extended

(12) Comprimento da linha

(13) Não uso de itálico

(14) Variação no desenho de tipos

(15) Uso de símbolos elou pictogramas claros

(16) Cor não é a única forma de

compreender a

informação

(17) Leitura da esquerda para direita

(18) Hierarquia das informações

\section{(19) Margens} adequadas

(20) Espaço formando blocos de informação
As famílias tipográficas em uso na embalagem

De acordo com as indicações. apresenta-se com devido contraste em suas formas.

No modelo utilizado, as ascendentes na área $D$ (texto "Via de administração"), escrito em Univers, e parecem estar adequadas a uma bola leitura, mesmo em tamanho reduzido. As descendentes aparecem no título "princípio ativo" utilizando Poynter Agate e são menos alongadas.

Com exceção das informações "nome comercial" e "princípio ativo" na área A e excluindo-se a área G desta análise, as demais utilizam condensed.

Nenhum dos textos fazem uso de extended.

O comprimento da linhas em todas as áreas é adequado para apresentação da informação.

$\mathrm{Na}$ área A, a informação "00xx" encontra-se em "Univers Oblique" que não se trata de itálico, porém que tem características formais próximas dele. Há pouca variação no desenho de tipos, sendo utilizadas especialmente duas famílias tipográficas.

Há dúvida quanto à legibilidade dos símbolos, especialmente aqueles observados na área G, com relação à sua proporção na embalagem e o contraste das linhas com o fundo.

A área "F" se configura em vermelho para indicar que é um medicamento com "restrição de prescrição". No entanto há o texto correlacionado a cor.

\section{As áreas estão organizadas de maneira que haja leitura da esquerda para direita.}

As informações se encontram organizadas de maneira hierárquica. Há dúvidas, no entanto, quanto ao devida destaque de determinadas informações em relação à sua importância na hierarquia dos dados apresentados ao usuário.

Considerando $\mathrm{X}$ como equivalente a $4 \mathrm{~mm}$ (tamanho mínimo ideal para fonte do título), as margens ficam estabelecidas em $2 \mathrm{~mm}$. Essa dimensão é baixa para margens, no entanto se for considerada como mínima, está adequada.

As áreas aparecem devidamente "separadas" com espaçamentos que permitem distingui-las do todo de maneira legível.

\section{Realizar estudos que} busquem testar a legibilidade do texto de "princípio ativo"

Realizar estudos substituindo 0 uso de condensed.

De acordo com as indicações.

De acordo com as indicações.

\section{Realizar estudos em "00xx"} que utilizem fontes não oblique e não itálico.

De acordo com as indicações.

Realizar estudos de
legibilidade dos símbolos que
constam na embalagem.

De acordo com as indicações.

De acordo com as indicações.

Realizar um estudo que determine a devida hierarquia das informações.

De acordo com as indicações.

De acordo com as indicações. 


\section{(C)] USIHC}

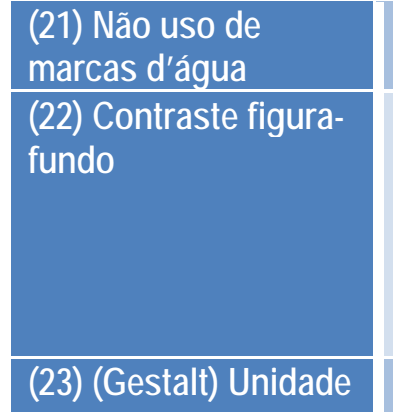

Não há uso de marcas d'água.

Há dúvidas quanto à espessura da linhas nos textos

que se encontram nas áreas C, D, E e G, assim como a espessura das linhas nos símbolos presentes nas áreas $E$ e G, especialmente quando o formato da embalagem for alterado ou reduzido. Essa espessura afeta diretamente a visualização figura-fundo.

A embalagem pode ser percebida como uma unidade, porém para melhor visualização dessa unidade no seu todo, seria necessário a comparação com as embalagens primária e terciária com as quais ela se relaciona.

\section{(24) (Gestalt)}

Segregação

\section{(25) (Gestalt)}

Unificação

\section{(26) (Gestalt)}

Fechamento

\section{(27) (Gestalt)}

Continuidade

\section{(28) (Gestalt)}

Proximidade

\section{(29) (Gestalt)}

Semelhança

\section{(30) (Gestalt) Simetria}

As partes podem ser segregadas em grupos de informações que se encontram separados por tipo de dado e a hierarquia entre eles determinada pela proporção ou por divisão espacial.

\section{Os elementos da embalagens encontram-se} unificados no seu todo, mas há possibilidade de estudos que venham a melhorar a relação entre eles.

A tendência de realizar fechamentos se aplica a essa embalagem especialmente na promoção de espaçamentos que funcionam como "separadores" de área e facilitam a hierarquização das informações. Também ocorre com a figura da área $B$, que faz menção à bandeira brasileira.

Sutilmente a continuidade aparece na área $A$, onde entende-se que a palavra "ativo" é continuação da frase que se inicia em "princípio". Porém, de forma geral o princípio de continuidade não se aplica a essa face.

A proximidade entre textos e entre símbolos e textos permite visualizar grupos de informações constantes na embalagem.

\section{Existem semelhanças entre as partes, porém estudos} poderiam ser realizados a fim de averiguar se tais semelhanças - como uso de fontes e cores parecidas - são benéficas à legibilidade das informações.

O formato da embalagem é simétrico, porém a parte gráfica encontra-se em assimetria de forma equilibrada. A proposição de plena simetria complicase pelas diferentes informações que precisam constar na embalagem.
De acordo com as indicações.

Realizar estudos quanto à devida proporção das letras e figuras em relação à espessura das linhas.

\section{Realizar estudos com a} relação gráfica e formal desta unidade (embalagem secundária) com o seu todo (primária e terciária).

De acordo com as indicações.

Realizar estudos que venham a melhorar a relação que promove a unificação das partes na embalagem.

De acordo com as indicações.

Realizar estudos de possíveis aplicações de continuidade, incluindo a relação entre as faces que compõem a embalagem.

De acordo com as indicações.

Realizar que estudos que analisem a harmonia e 0 contraste proporcionados pelas partes que compõem a embalagem.

Realizar estudos quanto a possibilidade de utilizar linguagem simétrica. 


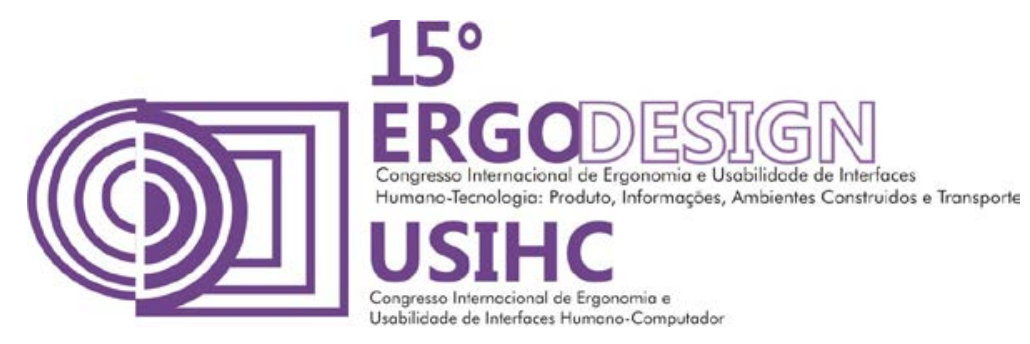

Das trinta indicações que foram consideradas para o estudo, destacaram-se com pareceres favoráveis - ou seja, de acordo com as proposições recomendadas em literatura - os quesitos indicados nos itens $1 ; 5 ; 6 ; 7 ; 8 ; 11 ; 12 ; 14 ; 16 ; 17 ; 19 ; 20 ; 21 ; 24 ; 26 ; 28$. Entre os pareceres que propõem a realização de estudos mais aprofundados em relação às características propostas nas indicações estão: 2; 3; 4; 9; 10; 13; 15; 18; 22; 23; 25; 27; 29; 30.

\section{CONSIDERAÇÕES FINAIS}

Limitações quanto aos aspectos que concernem a definição do termo "legibilidade" e estudos mais aprofundados de sua relação com a leiturabilidade e a visibilidade - inclusive em termos de sua abordagem na legislação brasileira na área da saúde - fizeram crer, a partir do estudo relatado neste artigo, que a pesquisa com rótulos de medicamentos requer uma abordagem particionada, de maneira a dar fundamento a um corpus teórico ainda em construção. Neste sentido, conclui-se expondo que o presente estudo é apenas uma parte inicial de múltiplos aspectos envoltos no design informacional aplicado no campo da saúde e da embalagem, sendo que outros passos ainda devem ser dados para a geração de pesquisas que venham a contribuir para a prática eficaz do design como meio comunicacional em rotulagens de medicamentos e, consequentemente, como forma que corrobore para a segurança do usuário.

Este estudo, desta forma, não é conclusivo no que se refere a proposição de uma embalagem que venha a atender de maneira mais efetiva os indicativos recomendados pelos autores, já que, para tanto, uma pesquisa mais ampla em termos de quantidade de tipos de embalagens de medicamentos deverá ser ainda realizada. A análise das embalagens em múltiplos colocados na armazenagem ou em ponto-de-venda e a identificação das mesmas por quem as manipula (farmacêuticos e usuários) seria também uma possibilidade de ampliação da pesquisa, visto que determinadas questões - como mancha de cor, relação entre formatos, legibilidade no contexto - só podem ser avaliadas no conjunto a partir de comparativos entre as partes.

Ainda, entende-se que mesmo nas questões onde se chegou a um parecer positivo com relação a análise realizada, ou seja, em que a embalagem estava de acordo com as indicações observadas em literatura, podem ser estudadas novas maneiras de apresentação que venham a melhorar a eficiência da informação. Indicações baseadas na Gestalt, por exemplo, estabelecem parâmetros de análise que não necessariamente resultam no parecer "positivo" ou "negativo", mas sim corroboram para revisões visuais que promovem a melhoria do produto e contribuem implementações ergonômicas mais eficazes.

\section{REFERÊNCIAS BIBLIOGRÁFICAS}

ABNT. Associação Brasileira de Normas Técnicas. NBR 9241-11: Requisitos Ergonômicos para Trabalho de Escritórios com Computadores Parte 11 - Orientações sobre Usabilidade. Rio de Janeiro: Abnt, 2002.

BRASIL. Rdc no 21, de 28 de março de 2012. Rdc 21/2009 Anvisa: Institui o Manual de Identidade Visual de Medicamentos do Ministério da Saúde e dá outras providências. Brasília, DF, 2012.

BRASIL. Rdc $n^{\circ} 71$, de 22 de dezembro de 2009. Rdc 71/2009 Anvisa : estabelece regras para a rotulagem de medicamentos. Brasília, DF, 2009. 


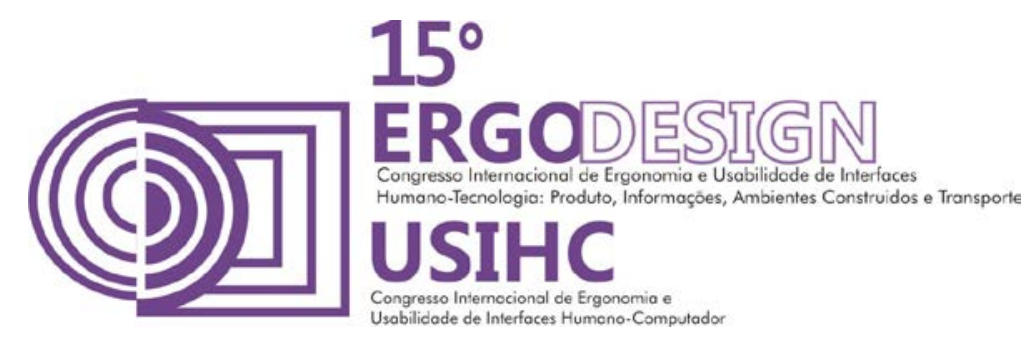

BRASIL. Agência Nacional de Vigilância Sanitária. Ministério da Saúda. O que devemos saber sobre os medicamentos. Brasília: Anvisa, 2010.

BRASIL. Anvisa. Ministério da Saúde. Portal da Agência Nacional de Vigilância Sanitária. 2014. Disponível em: <http://portal.anvisa.gov.br/>. Acesso em: 20 nov. 2014.

CASSIANI, Sílvia Helena de Bortoli. A segurança do paciente e o paradoxo no uso de medicamentos. Revista Brasileira de Enfermagen, Brasília, v. 1, n. 58, p.95-99, fev. 2005.

CASTILHO, S. R.; VENTURE, J.. Análise das atividades de dispensação de medicamentos no Instituto Municipal de Assistência à Saúde Nise da Silveira, visando à implantação da atenção farmacêutica a grupos de risco. Revista Brasileira Farmacêutica, Brasil, v. 3, n. 85, p.81-83, dez. 2004.

CAVACO, Afonso; SANTOS, Ana Lídia. Avaliação da legibilidade de folhetos informativos e literacia em saúde. Revista Saúde Pública, Lisboa, v. 5, n. 46, p.918-922, abr. 2012.

COMMITTEE ON SAFETY OF MEDICINES (Reino Unido). Medicines And Healthcare Products Regulatory Agency. Always Read The Leaflet: Getting the best information with every medicine. Norwich: The Stationery Office, 2005.

cossío, Maria González de. Process to implement new medicine guideline in Mexico. Infodesign: Revista Brasileira de Design da Informação, São Paulo, v. 5, n. 3, p.13-23, dez. 2008.

DONDIS, Donis A. Sintaxe da linguagem visual. 2. ed. São Paulo: Martins Fontes, 2007.

EUROPEAN COMMISSION. Guideline on the readability of the labelling and package leaflet of medicinal products for human us: Revision 1, 12 January 2009. Bruxelas: European Commission Enterprise And Industry Directorate-general, 2009.

FARIAS, Priscila L. Tipografia digital: impacto das novas tecnologias. Teresópolis: 2ab, 2013.

FONTOURA, Antônio M.; FUKUSHIMA, Naotake. Vade-Mécum de tipografia. Curitiba: Insight, 2012.

FRASCARA, Jorge. Diseño gráfico para la gente. Buenos Aires: Ediciones Infinito, 2000.

FUJITA, Patrícia Tiemi Lopes. A comunicação visual de bulas de remédios: análise ergonômica da diagramação e forma tipográfica com pessoas de terceira idade. Infodesign: Revista Brasileira de Design da Informação, São Paulo, v. 1, n. 1, p.51-54, dez. 2004.

FUJITA, Patricia Lopes; SPINILLO, Carla Galvão. Design da informação em bulas de medicamento: análise e classificação da estrutura e apresentação gráfica de seu conteúdo textual. Infodesign: Revista Brasileira de Design da Informação, São Paulo, v. 5, n. 3, p.1-12, dez. 2008.

GALATO, Dayani et al. A dispensação de medicamentos: uma reflexão sobre o processo para prevenção, identificação e resolução de problemas relacionados à farmacoterapia. Revista Brasileira de Ciências Farmacêuticas, Tubarão, v. 44, n. 3, p.465-475, set. 2008.

GIMENO, José Maria Iváñez. La gestión del diseño en la empresa. Madrid: Mcgraw-hill, 2000.

GOMES FILHO, João. Gestalt do Objeto: Sistema de Leitura Visual da Forma. 9. ed. São Paulo: Escrituras, 2012.

GURGEL, Floriano do Amaral. Administração da embalagem. São Paulo: Thomson Learning, 2007.

HELLEBEK, Annemarie et al. Patient safety in drug label design: analysis of reported adverse events before and after introducing a new label design. European Journal Of Hospital Pharmacy, London, v. 20, n. 4, p.212-217, ago. 2013.

ISO. International Organization for Standardization. ISO/IEC GUIDE 37:1995 (REVISION): Instructions for use of products by consumers. Geneva: International Organization For Standardization, 2009. 31 p. 


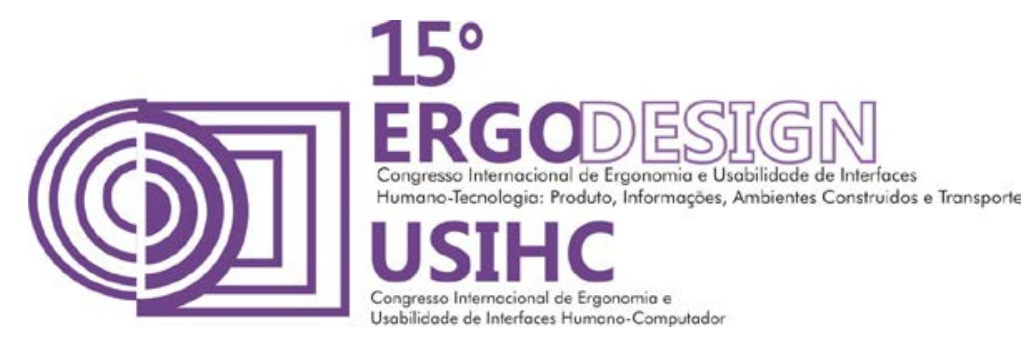

IIDA, Itiro. Ergonomia: projeto e produção. 2. ed. São Paulo: Blucher, 2005.

KAMISAKI, Margareth Sayuri; NASCIMENTO, Roberto Alcarria do; SANTOS, João Eduardo Guarnetti dos. Bulas e Cartelas de Medicamentos: Possíveis soluções de leiturabilidade através do Design Gráfico. Arcos Design, Rio de Janeiro, v. 6, n. 1, p.42-59, dez. 2011.

LIMA, Vera Lopes de Abreu. Legibilidade e leiturabilidade das bulas de medicamentos presentes no tratamento de pacientes cardíacos. 2007. 1 v. Dissertação (Mestrado) - Curso de Design, Pontifícia Universidade Católica do Rio de Janeiro, Rio de Janeiro, 2007.

MATOS, Alexandre Souza. A importância da informação do produto farmacêutico na linha de frente do comércio varejista: valor da informação e percepção. 2007. 78 f. Dissertação (Mestrado) - Curso de Programa de Pós-graduação em Engenharia e Gestão do Conhecimento, Universidade Federal de Santa Catarina, Florianópolis, 2007.

MARTINS, Ricardo. Desafios na definição e medição da legibilidade, sob o ponto de vista do Design da Informação. Infodesign: Revista Brasileira de Design da Informação, São Paulo, v. 5, n. 3, p.57-61, dez. 2008.

MOURA, Reinaldo A.; BANZATO, José Maurício. Embalagem, unitização e conteinerização. 2. ed. São Paulo: Imam, 1997.

PASCHOARELLI, Luis C.; BONFIM, Gabriel H. C.. Ergonomics and interfaces of traditional information systems: Packaging. Infodesign: Revista Brasileira de Design da Informação, São Paulo, v. 10, n. 3, p.313-322, dez. 2013.

PAULA, Cristiane da $S$. et al. Análise crítica de bulas sob a perspectiva do usuário de medicamentos. Visão Acadêmica, Curitiba, v. 10, n. 2, p.123-133, dez. 2009.

PLAIN ENGLISH CAMPAIGN. Guide to design and layout. New Mills: Plain English Campaign, 2007.

PLAIN ENGLISH CAMPAIGN. How to write medical information in plain English. New Mills: Plain English Campaign, 2001.

TONETTO, Leandro Miletto; RENCK, Priscila Brust; STEIN, Lílian Milnitsky. Cognição, design e consumo: A racionalidade limitada na tomada de decisão. Estudos em Design, Rio de Janeiro, v. 20, n. 2, p.1-18, dez. 2012.

SPINILLO, Carla Galvão; PADOVANI, Stephania; LANZONI, Cristine. Ergonomia informacional em bulas de medicamentos e na tarefa de uso: um estudo em fármaco em suspensão oral. Ação Ergonômica: Revista da Associação Brasileira de Ergonomia, Rio de Janeiro, v. 5, n. 1, p.2-10, dez. 2010.

WAARDE, Karen van Der. Designing information about medicine for people. Infodesign: Revista Brasileira de Design da Informação, São Paulo, v. 5, n. 3, p.37-47, dez. 2008.

\section{AGRADECIMENTOS}

À Coordenação de Aperfeiçoamento de Pessoal de Nível Superior (CAPES), ao Programa de Pós-graduação em Design da UFSC (PPGD/UFSC), ao Núcleo de Gestão de Design e Laboratório de Design e Usabilidade da UFSC (NGD-LDU/UFSC). 